\title{
Erratum to: Video Summarization Based Tele-endoscopy: A Service to Efficiently Manage Visual Data Generated During Wireless Capsule Endoscopy Procedure
}

\author{
Irfan Mehmood • Muhammad Sajjad • Sung Wook Baik
}

Published online: 10 September 2014

(C) Springer Science+Business Media New York 2014

Erratum to: J Med Syst (2014) 38:109

DOI 10.1007/s10916-014-0109-y

The original version of this article unfortunately contained a mistake. Figure 3 was partially displayed and the complete view of the figure is missing. The correct Fig. 3 image is shown below:

The online version of the original article can be found at http://dx.doi.org/ 10.1007/s10916-014-0109-y.

I. Mehmood $\cdot$ M. Sajjad $\cdot$ S. W. Baik $(\bowtie)$

College of Electronics and Information Engineering, Sejong

University, Seoul, Republic of Korea

e-mail: sbaik@sejong.ac.kr

I. Mehmood

e-mail: irfanmehmood@sju.ac.kr

M. Sajjad

e-mail: sajjad@sju.ac.kr 
Fig. 3 Saliency maps. From top to bottom: input image and its corresponding saliency map

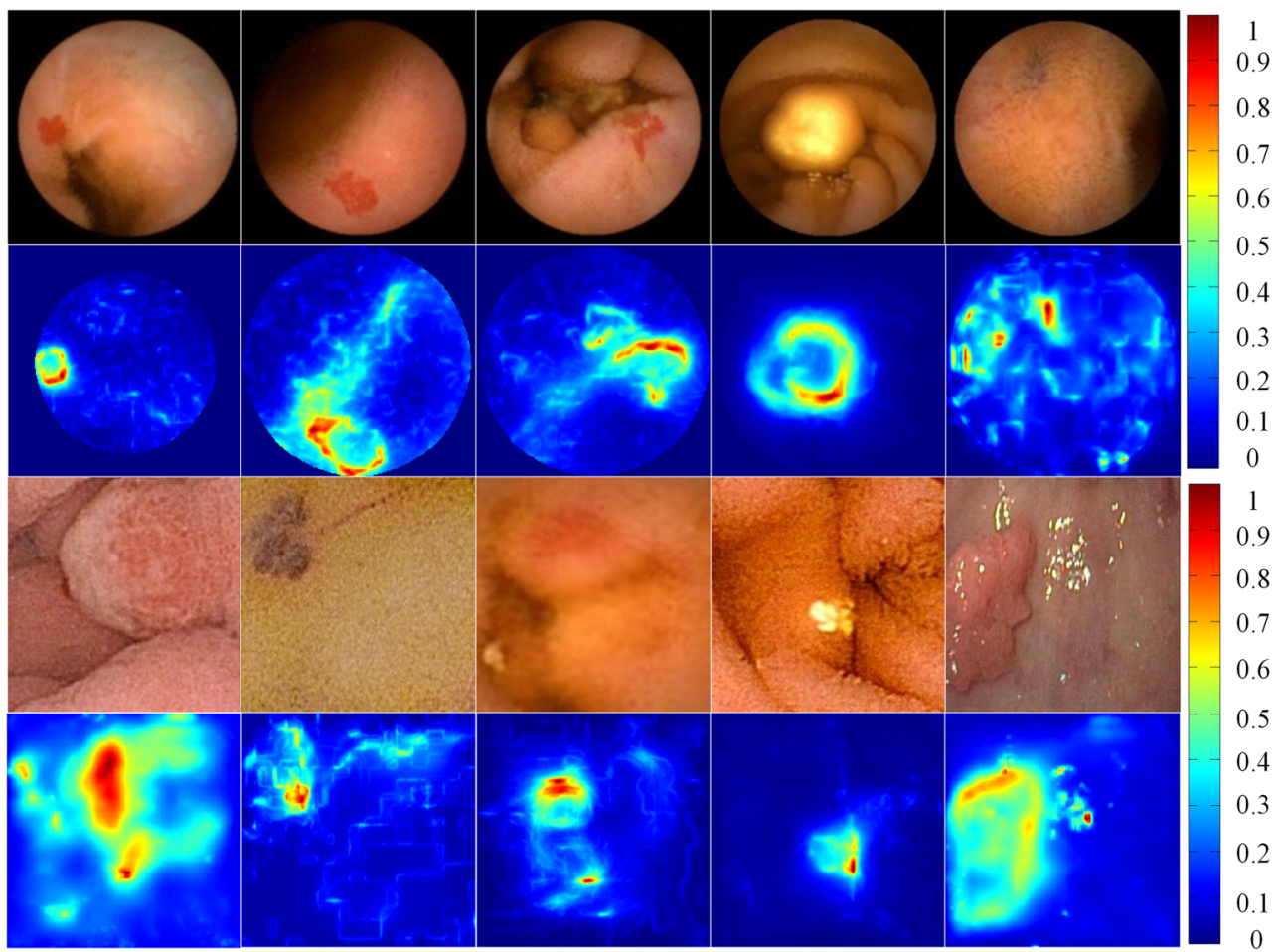

